\title{
Gentrification: os centros históricos e a nova realidade urbana pós-moderna
}

\author{
C. H. P. CUNHA* \\ Instituto Federal de Educação, Ciência e Tecnologia do Rio Grande do Norte \\ carlos.cunha@ifrn.edu.br*
}

Artigo submetido em 03/09/2014 e aceito em 28/02/2019

DOI: $10.15628 /$ holos.2019.2368

\section{RESUMO}

As práticas de recuperação de centros históricos urbanos, notadamente nos anos 1990, concentraram-se em embelezar esses espaços históricos, disciplinando as suas práticas e formas de consumo. Esse tipo de intervenção urbana, marca da pós-modernidade, da sociedade de consumo e dos espaços "simulacionais", pode ser classificada como gentrification. Assim, a questão não era necessariamente a preservação e restauração de bens históricos da cidade, mas, sim, a restauração daqueles bens que pudessem de forma mais eficiente ser embelezados, empacotados e vendidos como mais um atrativo da cidade. Esse processo ocorreu em dezenas de cidades espalhadas pela Europa, Estados Unidos e América Latina como um todo. No Brasil, podemos destacar ações intensivas dessa natureza em centros históricos como a Lapa, no Rio de Janeiro, o Pelourinho, em Salvador, o Recife Antigo, o Centro Histórico de São Luís do Maranhão, dentre tantos outros.

PALAVRAS-CHAVE: Gentrification, Urbanismo, Pós-Modernidade.

\section{Gentrification: historical city centers and the new postmodern urban reality}

\section{ABSTRACT}

The recovery practices of urban historic centers, notably in the 1990s, focused on beautifying these historical spaces, disciplining their practices and forms of consumption. This type of urban intervention, a hallmark of postmodernity, consumer society and "simulational" spaces, can be classified as gentrification. Thus, the issue was not necessarily the preservation and restoration of the city's historic assets, but the restoration of those assets that could most effectively be embellished, packaged and sold as yet another attraction of the city. This process occurred in dozens of cities across Europe, the United States, and Latin America as a whole. In Brazil, we can highlight intensive actions of this nature in historical centers such as Lapa, in Rio de Janeiro, Pelourinho, in Salvador, Recife Antigo, São Luís do Maranhão Historic Center, among many others.

KEYWORDS: Gentrification, Urbanismo, Postmodernity. 


\section{APRESENTAÇÃO}

Devido, dentre outras coisas, ao grande crescimento urbano no "mundo ocidental", após os anos 1950 e aos problemas socioeconômicos decorrentes desse avanço, bem como, ao acirramento das disputas pelos espaços urbanos centrais ${ }^{1}$, percebemos que os olhares dos poderes públicos atrelados aos interesses do capital imobiliário e turístico voltaram-se com força para os denominados centros históricos. Essas mudanças se processaram em fins dos anos $1960 \mathrm{e}$ 1970 na Inglaterra e Estados Unidos e, notadamente a partir da segunda metade dos anos 1980 e ao longo dos anos 1990, na América Latina.

Porém, o que se discutia nesses programas de "retorno" aos centros históricos urbanos, não era mais a demolição de casas e construção de avenidas largas, de fácil circulação, livre dos "miasmas" e consequentemente "sadias", marcas da "terra arrasada" hausmanizante do final do século XIX e início do século XX, mas, sim, a preservação de um conjunto de bens históricos das cidades e um aproveitamento desses bens a partir de uma lógica de mercado, voltado à construção de um espaço enobrecido, economicamente viável e possível de ser explorado por uma parcela da população com poder aquisitivo elevado e, até mesmo, servir de atração turística.

Seja a partir de um discurso de modernização, mostrando a necessidade de mais "saúde" para a cidade, marcas das reformas urbanas do início do século $X X$, ou pela busca de uma exploração econômica dos bens históricos, dentro da lógica da city marketing pós-moderna, essas ações voltadas os centros históricos mantiveram um caráter essencialmente elitizado. Ambas, contribuíram para a construção de espaços de sociabilidades fragmentados e praticados primordialmente por grupos socioeconômicos mais elevados. Assim, a haussmanização, no início do século XX, e gentrification, no fim do mesmo século, podem ser analisadas como similares em suas posturas espacializantes e socialmente excludentes.

Esse "retorno" aos Centros Históricos foi motivado também pela percepção, por parte da gestão pública e do empresariado local, do enorme "desperdício" econômico e imobiliário que o "abandono" dessas áreas centrais e históricas acabava gerando. Num dado momento esses gestores e empresários perceberam naquelas áreas outro filão, não apenas cultural, mas, também, um grande potencial econômico. Cultura e economia juntas no inadiável projeto de construção de uma imagem positiva da cidade, contribuindo de forma decisiva no universo da disputa, entre várias urbes mundo a fora, para captar investimentos e turistas.

Além da ampliação das noções patrimoniais e de uma maior democratização na participação dos processos preservacionistas no "mundo ocidental", as décadas de 1970 e 1980 articularam também uma mudança significativa nessa relação com os bens histórico-artísticos, notadamente os centros históricos urbanos, que foi justamente a noção de conservação integrada. O que estava em jogo agora, não era mais tão somente a preservação da materialização arquitetônica do bem patrimonial, mas também todo um universo social e econômico contido em seu entorno. Assim é que os centros históricos passaram a ganhar mais importância nessas políticas e projetos urbanísticos que, ao invés de simplesmente abandonar ou demolir características de uma política de "terra arrasada haussmaniana", passaram a pensar em políticas de "revitalização", ressignificação e revalorização econômica dessas áreas. 
As cidades pós-modernas, gradativamente a partir dos anos 70, passaram a se configurar como centros de consumo, espaços fragmentados ricos em signos e imagens e voltados para o entretenimento não só local, mas global, após a consolidação de uma prática turística internacional. Uma manifestação concreta desse processo é justamente a proliferação de espaços e redutos urbanos, que transformaram o lazer e o consumo em destacadas "experiências" individuais e coletivas distintivas, como: shopping centers, parques temáticos, galerias de arte, ruas revitalizadas, voltadas para uma concepção cultural mais pop, grandes complexos culturais, bem como a "revitalização" de centros históricos, voltados agora para a realização de eventos culturais e turísticos.

$\mathrm{Na}$ sociedade de consumo vive-se a era dos objetos, de acordo com o seu ritmo, permanências e mudanças (Baudrillard, 1995, p. 15). Partindo dessa concepção, percebemos que a pós-modernidade impôs uma nova relação entre pessoas, objetos de consumo e sociedade. Não nos referimos mais a utilidade inicial e conceitual de um determinado objeto consumível, mas sim, a um corpo de elementos significantes arrastando o consumidor por uma carga motivacional consumista muito complexa. Esses recursos muitas vezes são potencializados pelos meios de comunicação em massa, cuja televisão, na maioria das vezes não apresenta o real, mas apenas "vertigem da realidade".

Em suma, na pós-modernidade não se consome os objetos e espaços, principalmente os urbanos, a partir de seus valores estritamente de usos, nos seus sentidos utilitários originais. Esses alvos e objetos de desejo do consumo acabam sendo saturados de signos que servem de elementos distintivos do indivíduo inserido em seu espaço social.

Sharon Zukin (1996) destaca a importância dos estudos sobre os espaços urbanos, como uma boa oportunidade de aplicação da ideia de pós-modernização e criação de paisagens urbanas estetizadas, quando, por exemplo, algumas áreas históricas são transformadas em uma obra de arte pronta para ser consumida. Ele discute como essa concepção pós-moderna e de sociedade de consumo - saturada de signos, mensagens e imagens - ajuda no entendimento do processo de reestruturação e reordenação das relações sócio espaciais urbanas, pelos novos padrões de investimentos e produção de imagens e signos agregados à urbe, bem como as maneiras pelas quais a apropriação cultural tornou-se uma estratégia de fortalecimento do valor econômico atrelado a esses espaços históricos e patrimoniais.

Partindo dessas análises de Zukin, percebemos que o retorno para os centros históricos, através de políticas de "revitalização", refuncionalização e valorização desses espaços urbanos fragmentados, é justamente uma tentativa de enfeitar, empacotar e comercializar o patrimônio e esses centros urbanos antigos; bem como, supervalorizar os aspectos econômicos/comerciais. Constrói-se uma imagem, um simulacro, e montam-se estratégias para a sua exploração econômica. Assim, segundo Choay

[...] os monumentos e o patrimônio históricos adquirem dupla função - obras que propiciam saber e prazer, postas à disposição de todos; mas também produtos culturais, fabricados, empacotados e distribuídos para serem consumidos. (2006, p. 211) 
Isso não implica em uma neutralização total do valor cultural, agregado a determinado bem histórico-artístico, em detrimento de seu valor econômico. O que ocorre é justamente o contrário. Os elementos simbólicos, históricos e identitários passam a ser cada vez mais resgatados, porém, com novos objetivos, motivações e simbologias. A partir dos anos 70 e, especialmente, nos anos 90, o histórico, o cultural e o antigo, adquiriram uma capacidade de agregar valor econômico, e passaram, também, a ser cada vez mais valorizados como algo cult, como afirma Huyssem:

[...] chamada restauração historicizante de velhos centros urbanos, cidades, museus e paisagens inteiras, empreendimentos patrimoniais e heranças nacionais, a onda da nova arquitetura de museus [...], o boom das modas retrô e dos utensílios retrô, a comercialização em massa da nostalgia, a obsessiva automusealização através da câmara de vídeo, a literatura memorialística e confessional, o crescimento dos romances autobiográficos e históricos pós-modernos [...] (Vargas \& Castilho, 2009, p. 16)

Dessa forma, ao mesmo tempo em que a paisagem urbana histórica, na lógica da exploração imobiliário-turística, precisa manter esse caráter histórico-identitários, acaba, também, agregando valor econômico. Dessa maneira, sofre uma espécie de "reprogramação" em relação aos laços sociais estabelecidos e aos construtores de sentido. Essa força renovadora e requalificante do capital procura estimular o desenvolvimento de múltiplas perspectivas de exploração e vivências no espaço urbano histórico, paradoxalmente, estabelece palimpsestos desarticuladores do caráter idiossincrático dos centros históricos urbanos e rompem seus laços sociais tradicionais.

O "regresso" das classes médias e altas aos centros históricos ocorreu num contexto cujas autoridades gestoras e partes dos investidores locais perceberam que as áreas históricas urbanas centrais não possuíam apenas uma importância cultural, mas também um grande potencial econômico. Nesse momento, valores culturais e valores econômicos entrelaçaram-se comprometidos com projeto de construção de uma imagem positiva da cidade, contribuindo de forma decisiva no universo de disputas entre várias urbes mundo a fora e tentando captar investimentos de turistas, como afirma Harvey (2009, p. 265):

O aumento da competição em condições de crise coagiu os capitalistas a darem muito mais atenção às vantagens localizacionais relativas, precisamente porque a diminuição das barreiras espaciais dá aos capitalistas o poder de explorar, com bom proveito, minúsculas diferenciações espaciais.

O valor econômico assumiu uma grande importância e primazia, porém, travestido de valor cultural histórico mantenedor de supostos laços identitários de uma região e de um dado grupo. Podemos, entretanto, assinalar uma pertinente crítica feita por Choay (2006), acerca dessa relação, pois as políticas de revitalização e revalorização do patrimônio com ênfase nos Centros Históricos urbanos, muitas vezes não estão a "disposição de todos", mas sim, são pensados para o consumo das classes média e alta. Sobre essa questão, afirma Zukin: 
[...] o processo social de construção de uma paisagem pós-moderna depende de uma fragmentação econômica das antigas solidariedades urbanas e de uma reintegração que está fortemente alterada pelos novos modos de apropriação cultural. A genialidade dos investidores imobiliários, nesse contexto, consiste em converter a narrativa da cidade moderna em um nexo fictício, uma imagem que é um grande embrulho daquilo que a população pode comprar, um sonho de consumo visual. (1996, p. 205)

O termo gentrification foi usado inicialmente para se referir ao processo de "repovoamento" de bairros antigos e desvalorizados de Londres, a partir dos anos 1960, principalmente por jovens famílias de classe média e com alto capital intelectual. Processo semelhante foi verificado em Nova lorque, no mesmo período, com a reocupação de bairros como Greenwich Village e Soho. Esse "retorno" aos "centros" teve na política habitacional sua primeira e principal justificativa. Em cidades como Nova lorque, Barcelona, Lyon, Bruxelas, dentre outras. Os financiamentos públicos possibilitaram que essas famílias adquirissem suas unidades habitacionais nos bairros em processo de "revitalização". Esse processo contrariava a tendência urbanística da época, voltada para a construção de condomínios de luxo nas áreas periféricas das urbes. (Bidou-Zachariasen, 2006, p. 15).

Para influenciar a transferência das famílias de classe média para os bairros históricos era necessário que esses espaços públicos apresentassem determinadas características, tais como: o melhoramento das estruturas físicas, iluminação, segurança, e certo controle sobre as atividades desenvolvidas pelas pessoas residentes nesses locais, onde, muitas vezes, estavam fora dos novos projetos pensados pelos agentes "gentrificadores". Visavam sempre uma possível valorização imobiliária desses bairros, embora, num passado recente, fossem centros de criminalidade e pobreza. Porém, gentrification não se refere apenas a uma reestruturação física dos bairros antigos, ela se concentra também em uma alteração funcional e simbólica desses bairros.

A questão da gentrification já vem sendo bastante estudada por autores como Neil Smith (1979 e 2006), Sharon Zukin (1996), David Harvey (2009), Mike Featherstone (1995), dentre outros. Em diversos trabalhos são utilizados termos como enobrecimento, gentrificação e gentrification, para se referir ao mesmo processo. Devido a falta de consenso e das, a nosso ver, infrutíferas discussões acerca dessa terminologia, optamos nesse artigo em manter o termo em seu original em inglês.

Entre os anos 1940 e 1950, ocorreu uma forte expansão periurbana em várias cidades europeias e norte-americanas. As camadas mais ricas passaram a se transferir para as periferias, em busca de mais segurança e qualidade de vida, no interior de fortificados condomínios. Na América Latina e no Brasil, esse processo de abandono do "centro" ocorreu mais nos anos 1960 e 1970. Essa tendência de ocupação elitizada das periferias levou, na maioria das vezes, a uma degradação das áreas centrais. Por fim, a deterioração de seus prédios antigos e a ocupação por uma população mais pobre e suas atividades cotidianas contribuíram para uma desvalorização desses espaços urbanos.

No final dos anos 1960 e início dos anos 1970, algumas grandes cidades europeias e norteamericanas começam a vivenciar uma nova perspectiva urbanística. Nesse processo podemos 
destacar como pioneira, a cidade de Londres, cujo processo de "retorno ao centro" foi assim descrito por Glass:

Um após o outro, numerosos bairros operários londrinos foram invadidos pelas classes médias altas e baixas. Locais degradados ou com casinhas modestas, com dois aposentos no térreo e dois em cima, foram retomadas quando os contratos de aluguel expiraram, e se tornaram elegantes residências de alto preço. Residências vitorianas maiores, que tinham mudado de função - ou seja, haviam passado a ser utilizadas como pensões familiares ou sublocadas - recuperaram novamente um bom nível de status. Esse processo de gentrificação, uma vez começado em um bairro, se estendeu rapidamente até que quase todas as camadas populares que aí moravam originalmente tivessem deixado o lugar e que todas as características sociais tivessem mudado. (Smith, 2006, p. 60)

Inicialmente limitadas a pequenas ações de "embelezamento" do patrimônio, acabaram se transformando em projetos mais audaciosos e complexos de alterações nas próprias práticas e agentes sociais, investimentos e valores econômicos desses espaços, motivando sérias discussões sobre as práticas de gentrification. Essas intervenções urbanas levaram a um "enobrecimento" dos Centros Históricos, fragmentando esses espaços, readequando suas paisagens e disciplinando o seu consumo e vivências ao turismo, lazer e entretenimento em suas diversas formas.

Nesse primeiro momento do processo de gentrification, ocorrido em Londres e em cidades com Nova lorque, os principais agentes "enobrecedores" foram os membros da classe média com um elevado capital cultural, que "não tinham receio de encostar nas massas populares" (Smith, 2006, p. 61) e que com suas práticas cotidianas e preferências culturais diferentes daquelas predominantes entre os antigos moradores desses centros urbanos socialmente decadentes, acabaram motivando também mudanças no próprio perfil de estabelecimentos comerciais que predominavam nesses espaços degradados e abandonados pelos poderes públicos. Porém, a partir dos anos 1980 e, principalmente, nos anos 1990, essas ações passaram a ser coordenadas pelo Estado e por empresas de diferentes segmentos, como o imobiliário, turístico, de entretenimentos e cultural.

É preciso deixar claro que as experiências de gentrification apresentam grandes particularidades, dependendo muito do contexto socioeconômico e cultural da população de cada recanto da cidade e de como essas estruturas conectam-se com os fluxos socioeconômicos nacionais e globais. Todavia, de forma geral, gentrification representa um retorno das elites de uma cidade para os centros e, consequentemente, uma expulsão - ou pelo menos uma tentativa - das classes populares desses espaços que passaram a ser cada vez mais enobrecidos e valorizados.

Um ponto bastante significativo a se discutir acerca dessas novas políticas urbanas pósmodernas é a utilização de expressões como regeneração ou revitalização urbana. Nesse caso, metáforas do corpo humano ou de processos biológicos são empregadas às questões urbanas. Essas expressões, cunhadas no campo da biologia, pode nos dizer muito acerca da essência dos 
discursos e práticas dos poderes públicos e dos empresários envolvidos nessas campanhas de "reconquista" dos centros históricos urbanos.

No final do século XIX e início do século XX, a comparação entre artérias e veias desobstruídas como condição para um corpo saudável, e as ruas das cidades, motivaram várias intervenções urbanísticas objetivando a construção de espaços abertos, amplos e avenidas largas, onde as pessoas análogas aos componentes do sangue podiam circular livremente, significando mais saúde ao corpo, assim como, às cidades. No final do século $X X$, porém, as "intervenções cirúrgicas" no corpo das cidades visavam muito mais um embelezamento e a construção de uma estrutura capaz de abrigar e de ser consumida por uma elite. Os pobres, nesse caso, são vistos como elementos a serem controlados e expulsos desses novos espaços, pois eles "apodrecem" o tecido urbano.

Seguindo posturas semelhantes às reformas urbanísticas haussmanizantes do final do século XIX e início do século XX, as práticas de refuncionalização de centros históricos urbanos, concentraram-se em embelezar o espaço histórico, disciplinando as suas práticas e formas de consumo. Na maior parte dos casos, atrelados ao turismo cultural e ao entretenimento. Esse tipo de intervenção urbana, marca da pós-modernidade, da sociedade de consumo e dos espaços "simulacionais", pode ser classificada como gentrification cultural.

Os processos de refuncionalização e gentrification nos centros históricos urbanos tenderam a transformar áreas que encontravam-se "marginalizadas" em destacados centros de entretenimento, com boates e bares sofisticados, restaurantes e até, em alguns casos, galerias de arte. Ainda sobre esses modernos programas de refuncionalização de centros históricos urbanos e seus impactos sociais, afirma Bidou-Zachariasen (2006, p. 36),

[...] se implementava uma espécie de gentrificação em termos de consumo e convívio, por meio da multiplicação de butiques, restaurantes, cafés 'da moda', espaços frequentados tantos pelos residentes como pela população de outros bairros e turistas, mas pertencentes às mesmas classes sociais, isto é, às classes médias altas (grifo nosso).

Podemos considerar, de forma geral, que gentrification se resume a empreendimentos econômicos que se voltam para determinados espaços da cidade, transformando-os em alvos de investimentos públicos e privados, enobrecedores e excludentes. Segundo Rogério Leite (2007, p. 62), "as políticas de gentrification podem ser consideradas sucessoras pós-modernas da experiência francesa bonapartista do final do século XIX". Seria, a nosso ver, uma espécie de neohaussmanização. Dessa forma, a marca dessas políticas urbanas pós-modernas são, principalmente, a tentativa de expulsão da população pobre das áreas urbanas centrais "revitalizadas" e a instalação de uma nova população com um poder aquisitivo mais elevado e com um capital cultural diferenciado, em relação aos moradores pobres dessas áreas.

\section{REFERÊNCIAS}

Ameson, F. (1985). Pós-modernidade e sociedade de consumo. São Paulo: Novos Estudos. 
Baudi, \& Baudrillard, J. (1995). A sociedade de consumo. Lisboa: Edições 70.

Baudrillard, J. (1991). Simulacros e simulações. Lisboa: Relógio D'Água.

Bidou-Zachariasen, Catherine. (2006). De volta à cidade: dos processos de gentrificação às políticas de "revitalização" dos centros urbanos. São Paulo: Annablume,.

Carlos, A. (1996). O turismo e a produção do não-lugar. Em E. YÁZIGI, A. CARLOS, \& R. CRUZ, Turismo: espaço, paisagem e cultura. São Paulo: Hucitec.

Featherstone, M. (1995). Cultura de consumo e pós-modernismo. São Paulo: Studio Nobel.

Harvey, D. (2009). A condição pós-moderna (18 ed.). São Paulo: Edições Loyola.

Leite, R. P. (2007). Contra-Usos da cidade: lugares e espaço público na experiência urbana contemporânea ( 2 ed.). Campinas: EDUFS.

Lyotard, J. F. (1986). O pós-moderno. Rio de janeiro: José Olympio.

Paes-Luchiari, M. T. (07 de dez de 2009). Centros históricos - Mercantilização e territorialidades do

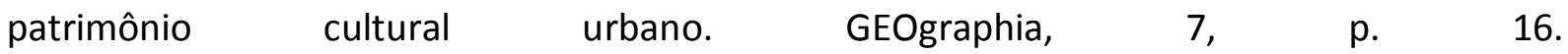
doi:https://doi.org/10.22409/GEOgraphia2005.v7i14.a13490

Sant'Anna, M. (2004). A cidade-atração: a norma de preservação de centros urbanos no Brasil dos anos 90. Tese (Doutoramento em Arquitetura e Urbanismo). Universidade Federal da Bahia.

Silva, A. (2001). Imaginários urbanos. São Paulo: Perspectiva.

Smith, N. (1979). Toward a theory of gentrification: a back to the city movement by capital, not people. Journal of the American Planning Association, 45, pp. 538-548.

Smith, N. (2006). gentrificação generalizada: de uma anomalia local à "regeneração" urbana como estratégia urbana global. Em C. Bidou-Zachariasen, De volta à cidade: dos processos de gentrificação às políticas de "revitalização" dos centros urbanos (pp. 59-87). São Paulo: Annablume.

Vargas, H. C., \& Castilho, A. H. (2009). Intervenções em centros urbanos: objetivos, estratégias e resultados ( 2 ed.). Barueri.

Vasconcellos, L. M., \& Mello, M. F. (2009). Re: atrás de, depois de.... Em H. C. Vargas, \& A. H. Castilho, Intervenções em centros urbanos: objetivos, estratégias e resultados (2 ed.). Barueri: Manole.

Zukin, S. (1996). Paisagens urbanas pós-modernas: mapeando cultura e poder. Revista do Patrimônio Histórico e Artístico Nacional(24). 